\title{
Two Cases of Blonanserin Induced Dyskinesia
}

\author{
1Dhananjay Chaudhari, ${ }^{2}$ Ganesh Shanker, ${ }^{3}$ Kunjan Gupta
}

\begin{abstract}
Blonanserin is an atypical antipsychotic with favorable outcome especially for negative symptoms of schizophrenia, and it also has some beneficial effects on cognition. It is well known that atypical antipsychotics have favorable adverse effect profile as compared to typical and conventional antipsychotics. As blonanserin is a relatively newer compound, so there is dearth of studies related to its side effect profile. Here we are reporting two cases of blonanserin induced dyskinesia.
\end{abstract}

Keywords: Blonanserin, Dyskinesia, Tardive Dyskinesia.

How to cite this article: Chaudhari D, Shanker G, Gupta K. Two Cases of Blonanserin Induced dyskinesia. Ind J Priv Psychiatry 2018;12(1):29-30.

\section{Source of support: Nil}

\section{Conflict of interest: None}

\section{INTRODUCTION}

Dyskinesia is a group of symptoms characterized by uncontrolled, involuntary movements, which can include muscles of the head, neck and extremities and reduced voluntary movements. Late onset of dyskinesia is known as tardive dyskinesia (TD), andit is a common adverse effect associated with the long-term use of neuroleptics, characterized by involuntary, repetitive body movements especially the tongue, jaw and / or extremities. ${ }^{1}$ TD occurs in 20 to $50 \%$ of patients treated with antipsychotic drugs. ${ }^{2}$ Annual occurrence of TD ranges from 2\% to $5 \%$ and the incidence of TD increases with age. Though it is known that the atypical antipsychotic have a reduced tendency to produce TD nonetheless extrapyramidal symptoms may occur during Blonanserintherapy. ${ }^{4}$ The "typical" neuroleptics with high dopamine D2 receptor occupancy have traditionally been reported to have a higher risk of causing TD than the "atypical" antipsychotics, with low D2 receptor occupancies, such as clozapine and quetiapine. However, it is now well recognized, that even atypical antipsychotic can cause TD. ${ }^{5}$

\footnotetext{
${ }^{1}$ Associate Professor and Head, ${ }^{2}$ Assistant Professor,

${ }^{3}$ Ex-Senior Resident

${ }^{1-3}$ Department of Psychiatry, Ganesh Shankar Vidyarthi Memorial Medical College, Kanpur, Uttar Pradesh, India
}

Corresponding Author: Dhananjay Chaudhari, Associate Professor and Head, Department of Psychiatry, Ganesh Shankar Vidyarthi Memorial Medical College, Kanpur, Uttar Pradesh, India, e-mail: georgiandc@gmail.com

\section{Case 1}

Miss X, a 23-year-old female presented in the psychiatry outpatient clinic with complaints of increased talkativeness, making tall claims, increased psychomotor activity, aggressive behavior and reduced sleep for last 2 months. According to the ICD-10 criteria she was diagnosed as mania with psychotic symptoms. To manage her symptoms, she was started on $4 \mathrm{mg}$ per day of blonanserin along with $2 \mathrm{mg}$ of Lorazepam at bedtime to manage her disturbed sleep. After two weeks of follow up improvement was noted in her symptoms, and hence she was continued on blonanserin therapy, with the dose being increased to $8 \mathrm{mg}$ of blonanserin per day. She was followed upfortnightly for the next 6 months. On every visit, she had gradual improvement of her affective symptoms. After 6 months of blonanserin $8 \mathrm{mg}$ per day, she developed abnormal oral movements including repeated stretching of one angle of mouth outwards which was suggestive of development of tardive dyskinesia. Her abnormal involuntary movement scale (AIMS) score was 9. She was referred to the neurology department where she was also diagnosed as a case of tardive dyskinesia. Her dose of Blonanserin was reduced to $4 \mathrm{mg}$ per day. After one month, the patient had a relapse and showed manic symptoms, for which she was admitted to the psychiatry ward and was started on aripiprazole $5 \mathrm{mg}$ along with Blonanserin $4 \mathrm{mg}$ and lorazepam $2 \mathrm{mg}$. She was also managed with an injectable antipsychotic (haloperidol $5 \mathrm{mg}$ ) to control her agitation. Her young mania rating scale(YMRS) score was 30. Her investigations, ncluding routine blood examination, non-contrast computed tomography scan of head, and thyroid profile were within normal limits. Gradually, Blonanserin was stopped and the dose of Aripiprazole was increased to $10 \mathrm{mg}$ per day. After discontinuation of Blonanserin, her abnormal oral movements improved gradually over a period of 20 days. Her treatment continued, and she responded well to Aripiprazole $10 \mathrm{mg}$ per day.

\section{CASE 2}

Mrs. Y, a 58-year-old female was admitted in the Psychiatry ward with complaints of fearfulness, irritability, muttering to self with inappropriate crying spells, reduced appetite, poor self-care, disturbed sleep and inability to work for the last 10 days. According to the International Classification of Diseases-10 (ICD-10) criterion, she was diagnosed with Other acute and transient psychotic disorder. To manage 
her symptoms, she was admitted to the psychiatric ward and was started on Blonanserin $4 \mathrm{mg}$ /day along with Lorazepam $2 \mathrm{mg}$ at bedtime to control her agitation and disturbed sleep. Her routine investigations were within normal limits. Blonanserin dose was gradually increased to $8 \mathrm{mg} /$ day. She gradually improved and was discharged with the satisfactory condition on Blonanserin $8 \mathrm{mg} /$ day and Lorazepam $2 \mathrm{mg}$ /day. After one week of therapy, the patient developed mild rigidity, slowness of movements, masked facial expressions, and tremors in upper limbs suggestive of extrapyramidal symptoms. So she was prescribed trihexyphenidyl $4 \mathrm{mg}$ per day. On subsequent follow up after 15 days her rigidity resolved but the patient developed tremors in the perioral region of face suggestive of oral dyskinesia. The dose of Trihexyphenidyl was increased to $6 \mathrm{mg} /$ day, and another second-generation antipsychotic Aripiprazole replaced Blonanserin. Her treatment continued, and she responded well to Aripiprazole $10 \mathrm{mg}$ per day.

\section{DISCUSSION}

Blonanserin is a 4-phenyl-2-(1-piperazinyl) pyridine. It acts as an antagonist at dopamine D2, D3, and serotonin 5-HT2A receptors. ${ }^{6}$ Blonanserin is pharmacologically more similar to first-generation antipsychotics than second-generation drugs, ${ }^{7}$ and probably the greater affinity for D2 receptors is responsible for the development of dyskinesia. However, these receptor binding profiles may minimize its potential to induce certain adverse effects such as orthostatic hypotension, sedation, weight gain, metabolic abnormalities, and peripheral anticholinergic side effects. ${ }^{8,9}$ Oral Blonanserin is generally well tolerated in patients of schizophrenia with most adverse reactions being of mild to moderate severity. ${ }^{10,11}$ In these two cases we observed blonanserin induced hypokinesia, perioral tremors and TD, which was also reported by Saraswathy et al. in $2015 .^{12}$

\section{REFERENCES}

1. Daniel DG, Egan MF, WolfSS. Neuropsychiatric aspects of movement disorders. In: Comprehensive Textbook of Psychiatry. 7th ed. Lippincott Williams \& Wilkins, Philadelphia, USA; 2000.

2. Waln O, Jankovic J. An update on tardive dyskinesia: from phenomenology to treatment. Tremor Other Hyperkinet Mov (N Y) 2013;12:3

3. Gebhardt S, Härtling F, Hanke M, et al. Prevalence of movement disorders in adolescent patients with schizophrenia and in relationship to predominantly atypical antipsychotic treatment.Eur Child Adolesc Psychiatry. 2006 Oct;15(7):371-382.

4. Lonansen $\AA$ (Blonanserin): prescribing information.Osaka: Dainippon Sumitomo Pharma Co. Ltd; 2009.

5. Peña MS, Yaltho TC, Jankovic J. Tardive dyskinesia and other movement disorders secondary to aripiprazole. MovDisord. 2011;26:147-152.

6. Une T, Kurumiya S. Pharmacological profile of blonanserin Jpn J ClinPsychopharmacol. 2007;10(7):1263-1272.

7. Miyamoto S, Fleischhacker WW, Lieberman JA. Pharmacologic treatment of schizophrenia. In: Lieberman JA, Murray RM, editors. Comprehensive Care of Schizophrenia (Second Edition): A Textbook of Clinical Management. New York: Oxford University Press; 2012. pp. 77-138.

8. Deeks ED, Keating GM. Blonanserin: a review of its use in the management of schizophrenia. CNS Drugs. 2010;24(1):65-84.

9. Oka M,Noda Y, Ochi Y, et al. Pharmacological profile of AD-5423, a novel antipsychotic with both potent dopamine-D2 and serotonin-S2 antagonist properties. J Pharmacol Exp Ther. 1993;264(1):158-165.

10. Miura S. Clinical evaluation of blonanserin for schizophrenia: a randomized study comparing blonanseria with risperidone. Jpn J ClinPsychopharmacol 2008;11:297-314.

11. Murasaki M. Clinical evaluation of blonanserin for schizophrenia: a double-blind trial comparing blonanserin with haloperidol. Jpn J ClinPsychopharmacol 2007;10: 2059-2079.

12. Saraswathy GR, Virupaksha HS, et al. Blonanserine induced hypokinesia and Tardive Dyskinesia.JMolBiomark Diag. 2015;6(6):254. 